\title{
Movement arrest and the hippocampus
}

\author{
D. CAROLINE BLANCHARD, ROBERT J. BLANCHARD, EUGENE M. C. LEE, \\ and KENNETH K. FUKUNAGA \\ University of Hawaii, Honolulu, Hawaii 96822
}

\begin{abstract}
Rats with hippocampal damage show a marked deficit in a variety of experiments requiring prolonged movement arrest. It is suggested that this inability of the hippocampal rat to "hold still" may be central in our understanding of the hippocampal syndrome.
\end{abstract}

In the rat, destruction of large areas of the hippocampus produces a dramatic and consistent syndrome of changes in a number of activities. Althought these effects are evident in a variety of tasks, including learned behavior, motor patterns, and activity, many investigators have assumed that there is a unitary deficit associated with hippocampal damage, one which is so pervasive as to affect numerous aspects of the animal's behavior.

In normal rats, an "active arrest" reaction tends to occur in the presence of strange or novel stimuli or environments (Blanchard, Kelley, \& Blanchard, 1974), or when the rat is confronted by inescapable predators (Blanchard \& Blanchard, 1972), attacking conspecifics (Blanchard, Fukunaga, Blanchard, \& Kelley, 1975), or previously neutral stimuli which have been paired with pain (Blanchard \& Blanchard, 1969). The animal appears to be alert and very much aroused, with high levels of muscle tension, and the receptors are usually oriented toward the threatening or novel stimulus. However, locomotion and other movements slow dramatically, or even cease, and the animal may be completely immobile for considerable periods. This "active arrest" reaction includes, but is not limited to, behaviors which have been called defensive immobility, crouching, or freezing.

There is consistent evidence that hippocampal damage produces a striking decrease in the incidence of crouching or freezing in the presence of conditioned threat stimuli (Blanchard \& Fial, 1968) or when placed with a predator (cat: Kim, Kim, Kim, Kim, Chang, Kim, \& Lee, 1971). Rats with hippocampal damage also fail to maintain an upright immobile "boxing" posture during the intervals between shock in reflexive fighting situations (Blanchard, Blanchard, \& Fial, 1970). It therefore appears likely that hippocampal damage may be characterized as producing a reduction in the active arrest reaction. The present experiments examine

Requests for reprints should be sent to D. Caroline Blanchard, Department of Psychology, 2430 Campus Road, Honolulu, Hawaii 96822. this hypothesis by measuring active arrest of movement for rats with hippocampal damage in a variety of tasks selected so as to involve immobility without pain or damage to the animal. These studies should therefore permit assessment of the generality of the "active arrest" notion of hippocampal functioning, and thus provides a clearer conceptualization of the mechanism damaged by hippocampal lesions.

\section{EXPERIMENT 1}

Rats with hippocampal lesions characteristically show more line crossings in large brightly lit open fields than do operated controls. However, this difference does not appear in smaller, dimly lit, compartments (Isaacson, 1974). Blanchard et al. (1974) have shown that open-field activity primarily reflects two fear-elicited defensive reactions-flight and freezing. When initially confronted with the open field, an intact rat shows (abortive) flight behavior; as the animal learns that escape is not possible, freezing becomes dominant. The present study examines freezing and flight for rats with hippocampal damage, in an open field, to determine if the pattern of results seen after hippocampal lesions may be attributable to alterations in movement arrest.

\section{Method and Procedure}

Subjects. The subjects were 20 naive male albino rats, 158159 days of age, from the colony maintained by the University of Hawaii Department of Psychology. These rats were randomly divided into a group of 11 , which received bilateral hippocampal lesions, and a group of 9, which were subjected to a sham operation.

Surgery and Histology. The 11 experimental rats received three bilateral electrolytic lesions, one in the anterior hippocampus $(2.6 \mathrm{~mm}$ posterior to bregma, $\pm 2.5 \mathrm{~mm}$ lateral, and $2.7 \mathrm{~mm}$ under the dura) and two in the posterior hippocampus ( $3.8 \mathrm{~mm}$ posterior to bregma, and $\pm 5.2 \mathrm{~mm}$ lateral, for both posterior lesions). The posterior lesions were made with the lesioning electrode at a 12-deg angle, such that after current had been passed through the electrode tip at its deepest extent in the hippocampus ( $4.6 \mathrm{~mm}$ under the dura), it could be withdrawn $2.0 \mathrm{~mm}$ and a second lesion made at an optimal location in the dorsal portion of the posterior hippocampus $(3.0 \mathrm{~mm}$ under the dura). The anterior lesion was $2.0 \mathrm{~mA}$, and $10 \mathrm{sec}$ in duration, while the two posterior lesions were $2.0 \mathrm{~mA}$, and $15 \mathrm{sec}$ in 
duration, for each lesion. Control animals sustained the same burr holes as did the experimental rats, but the electrode was lowered to the dorsal border of the hippocampus (at both anterior and posterior sites) and withdrawn without passage of current.

After all tests had been completed, the animals were sacrificed with an overdose of Nembutal, and perfused through the heart with physiological saline, followed by a $10 \%$ Formalin solution. Frozen sections at 50 microns were taken through the lesion site, with every fourth section mounted and stained with cresyl violet. The extent of damage to the hippocampus and to adjacent structures was analyzed by projection of the sections against a standard atlas section through the same level.

Histological results. As a result of histological examination of experimental and control rat brains, one experimental animal was eliminated because of a brain infection producing gross ventricular enlargement and one was eliminated due to extensive medial geniculate damage. The nine remaining experimental animals had extensive hippocampal damage, with more than $85 \%$ of the hippocampus destroyed, but with only slight, or unilateral, damage to adjacent structures, such as the geniculate bodies, entorhinal cortex, or anteromedial thalamic nuclei. Cortical and callosal damage in these rats was largely restricted to the area of electrode entry, and was very much equivalent to the damage seen in similar structures in control rats, for which this was the only damage seen. As a result of the elimination of two experimental rats, there were nine experimental and nine control animals.

Apparatus. The test apparatus consisted of a $90 \times 90 \mathrm{~cm}$ square open field, $28 \mathrm{~cm}$ deep. The field was constructed of standard plywood, unpainted, with a single $100-\mathrm{W}$ bulb suspended directly above the center. The floor of the apparatus was divided into 16 equal squares, $22.5 \mathrm{~cm}$ on each side.

Procedure. Thirteen days after surgery, all animals were placed individually in one corner of the open field, and allowed to explore for $12 \mathrm{~min}$. The following behaviors were recorded: line crossings (side and center crossings were tallied separately), freezing frequency, and duration of freezing. A line crossing was scored when all four limbs of the rat crossed a line. All other behavioral categories were rated in accordance with the definitions of Blanchard and Fial (1968).

\section{Results and Discussion}

Figure 1 presents the mean number of line crossings per minute, for each 2-min period during the test session. As this figure indicates, line crossings were not substantially different early in the session, but line crossings were higher for the experimental subjects during the latter portions of the session. In view of the finding that forced exploration of a novel open field produces initial flight attempts following by freezing (Blanchard et al., 1974), it was expected that any hippocampal-control differences in line crossings would emerge after an initial period of activity. To test this hypothesis, the data were

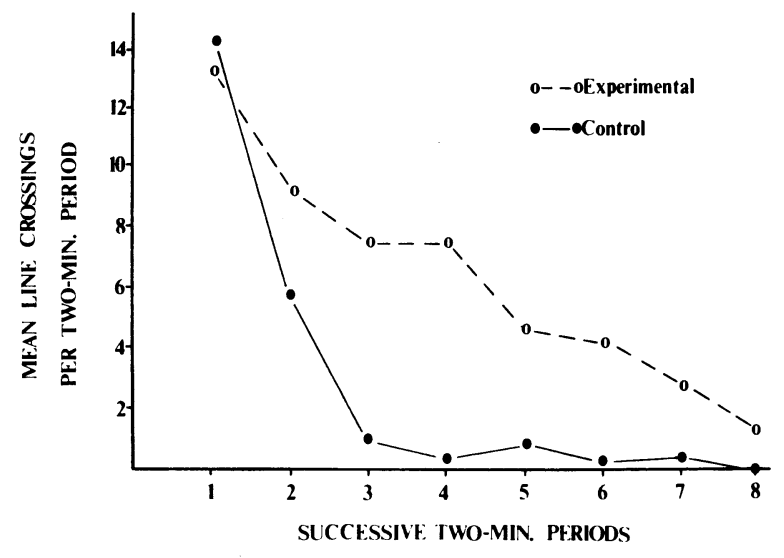

Figure 1. Mean line crossings during a 12-min open-field test session for rats with hippocampal lesions (experimental) or operated control rats.

divided into an initial, 4-min period, and the remaining period of Minutes 5-12. Table 1 presents each of the response measures taken during these two portions of the test session.

As Table 1 indicates, experimental rats made reliably more line crossings than controls, during the final $8 \mathrm{~min}$ of the test session $[\mathrm{T}(16)=2.13, \mathrm{p}<$ $.05]$, but not during the first $4 \mathrm{~min}(\mathrm{t}=.22)$. Total freezing durations were also reliably shorter for rats with hippocampal damage during the latter moments of the session $[\mathrm{t}(16)=3.53, \mathrm{p}<.01]$, but not in the initial period $(\mathrm{t}=.13)$.

It is interesting to note, however, that freezing frequency (i.e., the number of times that each rat initiated a freezing behavior) was not reduced for the experimental subjects. In fact, hippocampal damage produced a reliably higher freezing frequency $[\mathrm{t}(16)$ $=4.08, \mathrm{p}<.001]$ during the latter but not during the initial $(t=.40)$ periods of the test session. As this comparison of freezing frequency and total freezing duration suggests, each freezing episode for the experimental rats during the latter portion of the session was shorter than that of the control animals $[t(16)=3.41, p<.005]$. It should be noted, however, that the time available for initiating a freezing episode (i.e., time when the subject was not freezing) was also greater for the rats with hippocampal damage, and that this might well account for the differences in the number of freezing episodes: over-

Table 1

Behavior of Rats with Hippocampal Damage or Controls During Minutes 1-4 and 5-12 of an Open-Field Test Session

\begin{tabular}{|c|c|c|c|c|}
\hline & \multicolumn{2}{|c|}{ Minutes 14} & \multicolumn{2}{|c|}{ Minutes 5-12 } \\
\hline & Experimental & Control & Experimental & Control \\
\hline Line crossings (per min) & 11.08 & 10.19 & 7.04 & .60 \\
\hline Freezing frequency (per min) & 2.97 & 2.75 & 3.46 & 1.63 \\
\hline Freezing duration (sec per min) & 10.60 & 10.92 & 29.10 & 45.50 \\
\hline Mean time for each freezing episode (sec) & 3.57 & 3.97 & 8.41 & 27.91 \\
\hline
\end{tabular}


all, it required about $8.9 \mathrm{sec}$ of nonfreezing time for an experimental rat to initiate a freezing episode and $8.8 \mathrm{sec}$ for a control rat. The freezing episode difference did not appear during the initial test session minutes, in which all freezing episodes for both groups tended to be rather brief, with flight the dominant mode of defensive behavior seen.

An additional aspect of the hippocampal-control differences may be seen by computing the time required to make each line crossing, using only those times when locomotion was possible, i.e., nonfreezing times. During the initial 4-min period of the test session, hippocampal and control rats both required between 4 and $5 \mathrm{sec}$ to make each line crossing: during the latter portions of the session, this figure was unchanged for the hippocampal rats. They continued to make a line crossing in about $4.4 \mathrm{sec}$. The control rats, however, became strikingly less ambulatory, even during those periods in which they were not freezing, requiring nearly $25 \mathrm{sec}$ to make each line crossing. This finding suggests that, although the freezing definition used is clearly capable of isolating behaviors which differentiate hippocampal-damaged and control rats, it may not be optimal for identifying the full range of movementarrest tendencies of these animals: even when the control rats were not freezing, they still failed to locomote at their usual rate. Thus the movement arrest differences between rats with hippocampal damage and controls may be even more profound than can be objectively measured using the present definition of freezing. Observations of the movements of fearful animals certainly suggest that these are spasmodic and constrained, while hippocampal rats in the same circumstances appear much more fluid and easy in their movement.

In part, the present experiment constitutes a replication of the finding (Isaacson, 1974) that hippocampal damage produces greater activity in a brightly lit open field. However, the present data describe rather more specific behavior alterations than a general increase in activity. First, hippocampalcontrol differences did not emerge until later minutes of the test session, a time which corresponds to a switch (in the normal rat) from flight to freezing as the dominant open-field behavior. Also, the locomotor changes seen are associated with the reliable decrease in total freezing, and in the duration of freezing per freezing episode, for rats with hippocampal damage. However, the number (though not the rate) of freezing episodes was increased rather than decreased for these rats, indicating that hippocampal damage produces an alteration of the maintenance of freezing, but does not disturb the rats' ability to initiate freezing. Finally, these results suggest that, during nonfreezing episodes later in the test session, control rats show an ambulatory slowing which is not paralleled by the experimental animals.

\section{EXPERIMENT 2}

Experiment 2 measured the ability of rats with hippocampal damage or of controls to perform three motor tasks in which failure resulted in falling. These tasks were selected so as to involve active balance (wire test), immobility (ledge test), or to be largely independent of the overall amount of motion (platform task).

\section{Method and Procedure}

Subjects. The subjects were those used in Experiment 1.

Apparatus. Three types of apparatus were used. The platform test involved a $12.5 \times 21 \mathrm{~cm}$ wood rectangle affixed horizontally atop a 30-cm-high stand.

For the ledge test, a $20 \times 32 \times 2 \mathrm{~cm}$ wood rectangle was upended on its long side and fastened to a firm base. The $32 \times 2 \mathrm{~cm}$ face thus formed the ledge, $20 \mathrm{~cm}$ above the base.

For the wire test, a length of wire, $5 \mathrm{~mm}$ in diameter, was strung between two supports, $21 \mathrm{~cm}$ above a table top.

Procedure. These tests were made 17 days after surgery for all rats. The rats were run sequentially in the platform, ledge, and wire tasks. This sequence was chosen in order to present the least traumatizing tasks first, a procedure which was also followed in the ordering of Experiments 1, 2, and 3. The subjects were given four trials with each apparatus; each trial was $60 \mathrm{sec}$ in duration or until the rat fell from the apparatus, whichever came first. On each task, immobility duration, latency to fall, number of recoveries, and number of fecal boli were recorded. A recovery was scored for the ledge or platform task when one or more paws fell off the apparatus and the rat successfully regained the apparatus with the displaced limb. A recovery was counted on the wire task when the rat lost its grip with a paw and then recovered its grip.

For each task, the subject was placed on the apparatus and gradually released when it appeared to be balanced or to have a good grip. For the platform and ledge tests, the rat was completely on top of the apparatus, while, in the wire test, rats were placed on the wire, hanging by the forepaws. Falls occurring within the first $2 \mathrm{sec}$ after release were not counted, and the subjects were immediately replaced.

\section{Results and Discussion}

Table 2 presents data on the platform, ledge, and wire tests, for all measures taken. As this table indicates, the only reliable differences on any measure were found for the ledge test, where experimental animals fell more often $[\mathrm{t}(16)=2.73, \mathrm{p}<.05]$ and sooner [t $(16)=2.42, \mathrm{p}<.05]$, and also showed less immobility $[\mathrm{t}(16)=2.47, \mathrm{p}<.05]$ than controls. Observations of activities during piloting of this procedure and during the three tests suggest that the lack of difference of experimental and control animals on the ledge and wire tests were due to the fact that immobility was not significantly involved in these tasks. That is, hanging suspended by the front paws from the wire required active balance, rather than 
Table 2

Behavior During Three Tests of "Movement Arrest" for Hippocampal and Control Rats

\begin{tabular}{|c|c|c|c|c|}
\hline & \multicolumn{4}{|c|}{ Measures } \\
\hline & $\begin{array}{c}\text { Mean } \\
\text { Latency to } \\
\text { Fall (sec) }\end{array}$ & $\begin{array}{l}\text { Mean } \\
\text { Number } \\
\text { of Falls }\end{array}$ & $\begin{array}{c}\text { Mean } \\
\text { Percent } \\
\text { Time } \\
\text { Immobile }\end{array}$ & $\begin{array}{c}\text { Mean } \\
\text { Number } \\
\text { of Re- } \\
\text { coveries }\end{array}$ \\
\hline & \multicolumn{4}{|c|}{ Ledge Test } \\
\hline \multirow[t]{2}{*}{ Control } & $\begin{array}{l}119.14 \\
198.68\end{array}$ & $\begin{array}{r}2.78 \\
.89\end{array}$ & $\begin{array}{l}15.84 \% \\
36.77 \%\end{array}$ & $\begin{array}{l}1.11 \\
1.44\end{array}$ \\
\hline & \multicolumn{4}{|c|}{ Platform Test } \\
\hline \multirow[t]{2}{*}{$\begin{array}{l}\text { Experimental } \\
\text { Control }\end{array}$} & $\begin{array}{l}230.66 \\
217.92\end{array}$ & $\begin{array}{l}.78 \\
.89\end{array}$ & $\begin{array}{l}43.89 \% \\
50.44 \%\end{array}$ & $\begin{array}{r}.44 \\
1.11\end{array}$ \\
\hline & \multicolumn{4}{|c|}{ Wire Test } \\
\hline $\begin{array}{l}\text { Experimental } \\
\text { Control }\end{array}$ & $\begin{array}{l}8.51 \\
8.38\end{array}$ & $\begin{array}{l}\text { (1) } \\
\text { (1) }\end{array}$ & $\begin{array}{l}.51 \% \\
.27 \%\end{array}$ & $\begin{array}{l}\text { (2) } \\
\text { (2) }\end{array}$ \\
\hline
\end{tabular}

Note-(1) All rats fell so no comparison can be made. (2) None of the rats made any recoveries.

immobility. Thus, little immobility was observed for either group, and hippocampal-damaged animals were not at a disadvantage. In the platform task, the platform used was sufficiently large that movement was not incompatible with balance on the platform. Since immobility was not required, the slightly (nonsignificantly) reduced immobility scores of the experimental group did not result in more falls.

On the ledge, however, maintenance of a relatively immobile, well-balanced stance was necessary to prevent falling. On this task, the finding of more, and earlier, falls was clearly associated with a hippocampal damage-linked deficit in the ability to maintain such an immobile posture. The results of these three tasks therefore suggest that the motor changes associated with hippocampal damage are restricted to situations in which performance is dependent on the ability to maintain an immobile posture, rather than reflecting a more pervasive alteration of skilled acts.

\section{EXPERIMENT 3}

The preceding two experiments show that prolonged crouching in an open field or transient freezing on a ledge is disrupted after hippocampal lesions. Blanchard and Blanchard (1972) have shown that another movement arrest behavior, prolonged postshock boxing, is also disrupted following hippocampal damage. The present experiment examines a movement arrest behavior characterized by a different posture, one which appears to serve as an operant in certain shock situations. Campbell and Teghtsoonian (1958) and Blanchard and Blanchard (1969) have reported that rats rapidly learn to grasp shock grids when receiving continuous constant-current shocks. Such grid grasping presumably reduces the sparking or arcing resulting from intermittent contact with the shock grids. The specific immobile posture associated with grid grasping is distinguishable from "crouching" in the presence of threatening but nonpainful stimuli, on topographic, as well as situational, grounds (Blanchard \& Blanchard, 1969).

\section{Method and Procedures}

Subjects. The subjects were those used in Experiments 1 and 2 .

Apparatus. The shock chamber was a $30 \times 27 \times 25 \mathrm{~cm}$ wooden box with a grid floor and with one side of clear Plexiglas to permit observation. A Grason-Stadler E106-GS shock source delivered scrambled shock to the grids. The shockbox was placed adjacent to a one-way vision mirror and was illuminated by a single 75-W bulb centered $1 \mathrm{~m}$ above the flooring.

Procedure. Twenty-three days after surgery, the rats were placed in the shockbox and given 0.4-mA shock through the grids during the entire 10-min experimental session.

The behavior rating categories were those used by Blanchard and Fial (1968), except that, instead of sampling, behavior was continuously monitored during the experimental session. The durations for each category except stand were recorded on electric clocks. The frequency and duration of the stand category were recorded on pulse counters.

\section{Results and Discussion}

Table 3 presents frequency of standing, total duration of standing, and mean durations of standing episodes during each minute of the test session for experimental and control animals. The remaining categories of behavior were not submitted to statistical analysis because they occurred too infrequently to be meaningfully analyzed. As this table indicates, rats with hippocampal damage stood significantly more often $[\mathrm{t}(16)=2.58, \mathrm{p}<.02]$, but for a shorter total duration $[\mathrm{t}(16)=2.66, \mathrm{p}<.02]$ and with a shorter duration per episode $[\mathrm{t}(16)=2.14, \mathrm{p}<.05]$ than controls. As in Experiment 1, this initiation of immobility from a nonimmobile activity appears to be unchanged: an average of approximately $8.5 \mathrm{sec}$ of activity preceded the initiation of standing for each group.

These results support the finding of Experiment 1 that rats with hippocampal damage freeze as frequently as controls, but for shorter durations. Experiment 3 extends this pattern of findings, indicating that maintenance, not initiation, of immobility is reduced after hippocampal damage, to a situation involving an operant response which minimizes the pain of shock.

Table 3

Standing During Continuous Shock for Hippocampal and Control Rats

\begin{tabular}{lccc}
\hline & $\begin{array}{c}\text { Frequency } \\
\text { Stand* }\end{array}$ & $\begin{array}{c}\text { Duration } \\
\text { Stand* }\end{array}$ & $\begin{array}{c}\text { Mean Duration } \\
\text { Each Stand }\end{array}$ \\
\hline Control & 1.73 & 45.61 & 26.36 \\
Experimental & 2.71 & 36.03 & 13.29 \\
\hline
\end{tabular}

*per min 
The additional finding of Experiments 1 and 3, of reliably more freezing episodes for experimental rats, appears to simply reflect an unchanged rate of initiation of immobility, combined with increased durations of activity for these animals. In conjunction with consistent reductions in the duration of active immobility, these findings suggest a motor, rather than a motivational or emotional, deficit for rats with hippocampal damage. Other results contraindicating an emotionality deficit of these rats include the finding of Experiment 2, that hippocampal alterations of performance in a task presumably motivated by fear of falling only appeared when the performance itself was dependent on active immobility. Moreover, Blanchard et al. (1970) reported that rats with hippocampal damage are normal or superior to controls in reacting appropriately to either an unconditioned fear stimulus (cat) or a conditioned fear stimulus (shock prod) when such fear was expressed as an active behavior.

In summary, the results of the present studies suggest that one major function of the hippocampus is to assist in the maintenance of the active arrest or active immobility behavior which is frequently, but not always, associated with fear or pain. This view is somewhat similar to that of Altman, Bruner, and Bayer (1973), who suggested that this structure serves as a behavioral brake on response emission, particularly in animals which would, except for the action of this brake, be moving. If this brake is equated with the active arrest reaction, the present results indicate that hippocampal damage produces a situation in which the braking occurs normally, but quickly fades. That is, these data indicate hippo- campal involvement in the maintenance of the mechanism of holding still, rather than in its initiation.

\section{REFERENCES}

Altman, J., Bruner, R. L., \& Bayer, S. A. The hippocampus and behavioral maturation. Behavioral Biology, 1973, 8, 557-596.

Blanchard, R. J., \& Blanchard, D. C. Crouching as an infex of fear. Journal of Comparative and Physiological Psychology, 1969, 67, 370-375.

Blanchard, R. J., \& Blanchard, D. C. The effects of hippocampal lesions on the rat's reaction to a cat. Journal of Comparative and Physiological Psychology, 1972, 78, 77-82.

Blanchard, R. J., Blanchard, D. C., \& Fial, R. A. Hippocampal lesions in rats and their effect on activity, avoidance and aggression. Journal of Comparative and Physiological Psychology, 1970, 71, 92-102.

Blanchard, R. J., \& Fial, R. A. Effects of limbic lesions on passive avoidance and reactivity to shock. Journal ofComparative and Physiological Psychology, 1968, 66, 606-612.

Blanchard, R. J., Fukunaga, K., Blanchard, D. C., \& Kelley, M. J. Conspecific aggression in the laboratory rat. Journal of Comparative and Physiological Psychology, 1975, 89, 1204-1209.

Blanchard, R. J., Kelley, M. J., \& Blanchard, D. C. Defensive reactions and exploratory behavior in rats. Journal of Comparative and Physiological Psychology, 1974, 87, 1129-1133.

Campbell, B. A., \& Teghrsoonian, R. Electrical and behavioral effects of different types of shock stimuli on the rat. Journal of Comparative and Physiological Psychology, 1958, 51, 185-192.

IsAaCson, R. The limbic system. New York: Plenum Press, 1974.

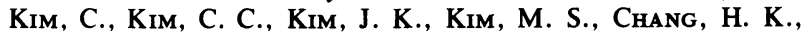
KIM, J. Y., \& LEE, I. G. Fear response and aggressive behavior of hippocampectomized house rats. Brain Research, 1971, 29, 237-251.

(Received for publication February 2, 1977; accepted April 28, 1977.) 